\title{
Desafíos para una teoría del arte: experiencia estética, institución y función social $^{1}$
}

\section{Challenges for an Art Theory: Aesthetic Experience, Institution and Social Functions}

\author{
Mario Alejandro Molano \\ Universidad Jorge Tadeo Lozano, Colombia \\ mario.molano@utadeo.edu.co
}

Resumen - A partir de las polémicas de fin de siglo xx en torno al arte de vanguardia, se inicia un replanteamiento de la teoría del arte desde al menos dos frentes: por un lado, debe revisarse el trabajo explicativo de la teoría del arte, y por el otro, el problema de la relación entre arte y sociedad para superar las dicotomías entre pureza y compromiso. Este ensayo propone un acercamiento a esta doble problemática. En primer lugar, se tratará de reinterpretar los problemas de la teoría del arte desde el marco de algunas discusiones de finales del siglo xx. En segundo lugar, se delimitarán dos variables fundamentales que la teoría del arte debería tener en cuenta en su labor comprensiva. Finalmente, se revisará una manera de entender la relación arte-sociedad que pueda escapar a la dicotomía de pureza y compromiso.

Palabras clave: Teoría del arte, Teoría estética, Vanguardia, Sociedad, Experiencia estética

Abstract - Considering certain polemics that surrounded the avant-garde on the xx century, the following essay will try to reinterpret Art Theory from two points of view: on the one hand, its explicative function, and on the other, the problematic relationship between art and society. These views must be revised in order to surpass the dichotomy of artistic purity and its commitment. This essay proposes an approximation to this dual problematic. At the first, it will try to reinterpret the problems of the Art Theory following a few discussions from the late twentieth century. Then, the paper will delimit two fundamental variables, which must be taken into account to understand its comprehensive function. Finally, it will come to an understanding about a sort of relationship between art and society that could be able to escape the dichotomy of purity and commitment previously mentioned.

Keywords: Art Theory, Aesthetics, Avant-garde, Society, Aesthetic Experience

Artículo producto de investigación del proyecto «Arte, Estética y Política» aprobado y financiado por la Unidad de Investigaciones de la Universidad Jorge Tadeo Lozano. 
El presente ensayo es un intento por reinterpretar la tarea comprensiva de la teoría del arte a la luz de algunas discusiones de final de siglo xx. En efecto, desde hace cerca de 50 años, no hay nada que cause más desconfianza entre teóricos y artistas contemporáneos que expresiones como «el Arte», «la obra de arte» y «la teoría del arte». Hay una porción de verdad en esta sospecha generalizada, pues en cierta medida, estos discursos han estado vinculados con ejercicios de legitimación de determinadas formas de arte sobre otras. Pero precisamente porque la sospecha es válida, el intento de revisar la tarea comprensiva de la teoría del arte es válido también. Si la teoría del arte ha sido frecuentemente denunciada como estrategia para institucionalizar prácticas, valores y concepciones determinadas, resulta necesario redescubrirla de un modo diferente, quizás incluso en sus preguntas fundamentales: ¿a qué llamamos arte?, ¿es incluso posible plantear una pregunta por «el arte»?, y de serlo, ¿a dónde apunta esa pregunta?, ¿qué buscamos con ella?, y ¿qué interés puede tener para nosotros tanto la pregunta como el arte mismo?

El replanteamiento de estas preguntas viene gestándose desde hace décadas. Buena parte de la discusión sobre estética y teoría del arte entre los años 70 y 80 giró en torno al problema del carácter institucional del arte, el desarrollo de su estatus de autonomía y la forma en que estaba relacionado con los procesos sociales de diferenciación propios de la modernidad. Podría decirse que estas discusiones han tenido básicamente dos caras. En primer lugar, a la luz del impacto de los movimientos de vanguardia, resurgió el motivo hegeliano de la muerte del arte, esta vez en un tono democratizador que se alejaba de la idea de progreso unidireccional del espíritu que Hegel le había dado en su momento. Desde este enfoque, las vanguardias adquirieron una importancia fundamental, puesto que nos habían hecho reconocer los límites históricos de toda forma de comprensión y producción de arte. La consecuencia no fue solamente la crisis de las teorías y los criterios de valoración tradicionales, sino también la crisis de la posibilidad misma de comprensión y valoración del arte (Danto, 49; Bürger, 62 y 167). Había que preguntarse nuevamente qué era lo que se buscaba con los intentos de teorizar el arte y cómo era posible esta teorización. Era urgente mostrar si la teoría del arte podía ser algo más que ideología, por ello había llegado el momento de ensanchar y problematizar el campo de fenómenos que debía tener en cuenta en sus explicaciones. Más aún, el propósito de la pregunta por el arte empezó a orientarse hacia el problema de la distinción misma del arte respecto a la multiplicidad de fenómenos no-artísticos.

La otra cara de las discusiones sobre estética y teoría del arte de fines del siglo xx se caracteriza por buscar salidas al exhausto debate entre partidarios del arte puro y del arte comprometido. Esta búsqueda generó, a su vez, el replanteamiento de la pregunta sobre el papel que juegan la experiencia estética y el arte en la sociedad moderna. Así surgieron básicamente dos tipos de discurso que formulan una perspectiva de integración del arte a la vida cotidiana, como forma de comunicación (Wellmer, 43; Gadamer, Verdad y método, 160; Jauss, 73), o bien plantean la irreductibilidad de la experiencia estética a códigos de comunicación y por tanto tienden a observar el arte como una especie de ruptura radical respecto a las estructuras sociales (Jean François Lyotard, 131). El antagonismo compromiso/autonomía se reformula entonces en términos de una suerte de integrismo del arte a la vida cotidiana y una suerte de mirada del arte como shock o trauma. A pesar de las nuevas dicotomías, esta perspectiva generó el retorno de la pregunta acerca del significado del arte para la vida humana. Adicionalmente, revitalizó 
la importancia de comprender ese papel del arte mediante una teoría que, más o menos implícitamente, constituía una defensa del arte frente a la colonización del mundo de la vida por la racionalidad instrumental y las lógicas del consumo.

En gran medida, estas discusiones de finales del siglo xx aún plantean desafíos para una teoría del arte, si se quiere, más comprensiva y dinámica. Con este marco de referencia inicial me propongo, en primer lugar, examinar la reorientación del esfuerzo comprensivo sobre el arte, y en segundo, proponer dos variables fundamentales que deben ser consideradas por una teoría del arte que asuma seriamente las discusiones heredadas del siglo xx. En tercer lugar, se hará un esbozo acerca del problema de la relación artesociedad y sus dicotomías.

\section{¿QUÉ SIGNIFICA PREGUNTARSE POR EL ARTE?}

Peter Bürger y Arthur Danto notaron cómo al menos hasta el surgimiento de las vanguardias históricas y el Pop Art, la comprensión del arte era identificada con la delimitación de procedimientos, medios y estilos determinados. Para Danto, el arte fue definido más o menos sucesivamente como representación, expresión y exploración de un medio (el color y la forma, el espacio, el lenguaje, el sonido). De igual modo, las transformaciones al interior de la historia del arte fueron comprendidas dentro de modelos teóricos que identificaban al arte con sus procedimientos y sus medios. Bürger y Danto coincidieron en mostrar que son precisamente estos modelos teóricos los que se ponen en crisis una vez surgen formas artísticas que no se dejan explicar fácilmente ni en términos de representación, ni en términos de medios o estilos. Para Bürger, este papel lo cumplen las vanguardias artísticas europeas de primera mitad de siglo $\mathrm{xx}$, las cuales no conllevan tan sólo una transformación de determinados procedimientos artísticos, sino una verdadera crítica de todo el conjunto de supuestos dominantes, esto es, una crítica radical a la institución del arte burgués europeo y a su estatus de autonomía (Bürger, 103). Para Danto, será el Pop Art el encargado de desafiar definitivamente tanto a la teoría del arte como a las formas de historiarlo que se derivarían de ella. Para él, la historia del arte, desde el Renacimiento hasta el Modernismo, es una sucesión de relatos y discursos que constriñen la idea de arte a un puñado de estilos y a una cierta línea de progreso histórico. El Pop Art habría puesto en crisis precisamente este tipo de relatos y discursos legitimadores, haciendo posible el pluralismo de estilos y liberadando al arte de una historia concebida en términos de progreso unidireccional (Danto, 150).

El campo del arte latinoamericano no fue tampoco ajeno a esta crisis. Podría pensarse que las experiencias de transgresión de los cánones de la Academia durante la primera mitad del siglo xx ya alentaban una revisión crítica de los modos de comprensión y creación del arte e incluso de la historia oficial que excluía la complejidad multicultural de nuestro continente. En Colombia, los artistas que trabajaron alrededor del muralismo, como Pedro Nel Gómez, Ignacio Gómez Jaramillo y Débora Arango, recibieron duras críticas que provenían tanto del frente ideológico conservador como de intelectuales liberales. El testimonio más crudo y radical de este rechazo lo representó el presidente de derecha Laureano Gómez, para quien el muralismo era testimonio de «pereza» y «degeneración» en el arte (162). Dos palabras muy cargadas de sentido que respondían 
muy bien al sistema de referencias académico para la comprensión del arte, cuyos pilares esenciales eran, por una parte, el amplio conocimiento y dominio de la técnica tradicional que acreditaba la virtud artística; y por otra, la elevación moral del artista y de sus temáticas. La evaluación de un crítico liberal como Jorge Zalamea, menos recordada pero también en una alta proporción negativa, tiende a coincidir con la de Laureano Gómez, cuando afirma que:

el mayor impedimento de Pedro Nel Gómez para realizar su ambiciosa empresa reside [...] en su desdén por la geometría, en la ceguedad que le impide descubrir las divinas leyes de relación de las que se desprende [...] el ritmo del universo pictórico. Sus frescos [...] pertenecen al primer día de la creación: todo en ellos es amontonamiento y confusión, sombra pululante de formas inconexas... (Zalamea, 301).

Los cuestionamientos que diversas corrientes artísticas del siglo xx plantean a las formas de comprensión tradicionales del arte dejan ver lo siguiente: en la medida en que los discursos críticos y teóricos operan como una estrategia de unificación y consolidación social e histórica de ciertas formas específicas del arte, quedan relativizados en sus pretensiones comprensivas y son vistos más bien como discursos ideológicos que responden a intereses de clase, de género y de dominio cultural. Esta crisis finalmente hará que desde la segunda mitad del siglo xx, las reflexiones sobre el arte problematicen la construcción misma del concepto de arte, del conjunto de fenómenos que son tomados como artísticos y las formas de entender sus dimensiones históricas y sociales. Desde entonces, toda teoría del arte se ve obligada a dar un paso atrás y tomar la forma de una metareflexión, esto es, una reflexión sobre los modos de teorizar los fenómenos artísticos. En este sentido, la primera línea de la Teoría Estética adorniana representaría el punto de partida de la teoría del arte aún hoy: «ha llegado a ser obvio que ya no es obvio nada que tenga que ver con el arte, ni en él mismo, ni en su relación con el todo, ni siquiera su derecho a la vida» (9).

El caso de la estética adorniana también es significativo porque es quizás el primer intento de asumir las consecuencias que conlleva esta nueva situación de la reflexión teórica sobre el arte en la que aún nos inscribimos. La primera de estas consecuencias radica en el reconocimiento de la historicidad de las categorías conceptuales de las que nos valemos en cada momento. Lo cual no significa sólo que toda reflexión conceptual está inexorablemente situada y en cierta proporción limitada por un marco histórico-social determinado, sino más aún que existe una relación dinámica entre el cambio histórico del objeto de estudio y los sistemas conceptuales que intentan hacer su reflexión intelectual (Bürger, 52). Esta relación no reduce necesariamente la reflexión conceptual a una mera expresión del espíritu de su época, sino que permite observar cómo las reflexiones conceptuales alcanzan mayor comprensión de su objeto de estudio y logran obtener para sus categorías conceptuales mayor alcance, en la medida en que acojan las variaciones históricas de sus objetos de estudio. La segunda consecuencia que implica este replanteamiento de la reflexión teórica sobre el arte, consiste en el desarrollo de una autoconsciencia acerca del papel sociocultural que desempeña. Esto significa en otras palabras que la teoría del arte ha dado un adiós, al parecer, definitivo a la ilusión cientifista de neutralidad sociocultural del discurso. Incluso, hoy resultan cuestionables las nuevas formas de proponer una posición tal de neutralidad, como la que representó el discurso post-histórico de Danto que promovía un tipo de pluralismo pasivo frente a la complejidad y la dinámica del arte. 
Por el contrario, la teoría del arte ha heredado desde el siglo pasado la conciencia de que su tarea consiste en pensar la radical importancia que posee eso que denominamos arte para la vida humana, desplegada a lo largo del tiempo y escenificada a través de configuraciones sociales cambiantes.

\section{VARIABLES DE INVESTIGACIÓN}

Desde este nuevo horizonte, el cual se viene configurando desde la segunda mitad del siglo $\mathrm{xx}$, se podrían identificar al menos dos variables mutuamente relacionadas, alrededor de las cuales se han ido desarrollando nuevos esfuerzos de teorizar y comprender los fenómenos artísticos. Estas variables son: la experiencia estética y el carácter social del arte en cuanto institución.

\section{Experiencia estética y construcción de sentido}

El problema de la experiencia estética se convierte en uno de los ejes centrales para la teoría del arte contemporánea, ya que sitúa las actividades de creación y recepción del arte en el escenario fundamental de los procesos de construcción y reconstrucción de sentido de mundo presentes en todo ser humano y en toda cultura, a lo largo de la historia, aunque inscritos cada vez en horizontes diferentes. Este enfoque deja sin sustento las teorías que intentan definir el carácter artístico en términos de rasgos formales, técnicos, estilísticos o históricos. Por el contrario, permite enfocar plenamente los procesos de construcción conceptual e institucional de aquello a lo que llamamos arte. Pero por otra parte, esta perspectiva también permite preguntarse por las estructuras básicas a las que respondería un tal modo de comprensión estética del mundo y sus formas diversas de realización histórica.

Algunos teóricos y críticos han empezado a dudar si realmente el concepto de experiencia estética juega aún algún papel en el arte contemporáneo, proclive a la desmaterialización, lo efímero y el juego - a veces transgresor, a veces humorístico-, con códigos culturales que recorren lo ancestral, lo popular, lo político e incluso lo publicitario. ¿Ha abandonado el arte su vínculo con lo estético?, ¿es realmente la experiencia estética uno de los desafíos que una teoría del arte debe confrontar justamente en un momento en el cual algunas prácticas artísticas parecen tan alejadas de la sensualidad de las formas?

El debate no deja de ser intenso e interesante cada vez que lo que se pone en juego es la comprensión del concepto mismo de experiencia estética, concepto hoy aún cargado de connotaciones clasicistas de armonía, equilibrio de la forma y composición. En otro nivel, este concepto suele estar asociado más bien a la idea del placer subjetivo, a las impresiones ópticas, táctiles, espaciales o auditivas y a sus asociaciones emocionales. Y, en efecto, desde estas resonancias no resulta plausible que el ensamblaje de un Cristo crucificado sobre el modelo de un avión de combate norteamericano (León Ferrari, La civilización occidental y la cristiana); los espejos de metal que revelan la imagen de una 
persona desaparecida al contacto con la respiración de los espectadores (Óscar Muñoz, Aliento); o las gigantescas proyecciones de mujeres trabajadoras mexicanas maltratadas sobre edificios institucionales en México, de Krzysztof Wodiczko (Tijuana Projection), estén diseñadas para la contemplación hedonista de las formas. Sin embargo, estas obras crean un espacio de ruptura en los flujos continuos de la vida cotidiana e introducen una suerte de suspensión de presupuestos, expectativas y significaciones habituales. Aunque estas obras ya no demarcan explícitamente el espacio que separa lo artístico del resto de espacios de actividad vital, sí hace parte de la experiencia de estas obras la sensación de haber atravesado de repente un umbral tras el cual nuestros horizontes de sentido deben volverse a abrir y replantearse. No se trata, pues, de que la experiencia estética esté vinculada con ciertos objetos, ciertos espacios, ciertos momentos; por el contrario, como muestran los tres ejemplos citados, puede verse cómo la experiencia estética puede activarse virtualmente en cualquier espacio y momento y apoderarse incluso de los objetos más anodinos: figuras de la cultura de masas, objetos esquivos a la percepción, espacios rutinarios y sujetos anónimos.

Pero encontramos también algo que puede ser fundamental para pensar el concepto de experiencia estética. En obras como las que hemos mencionado, el efecto de desconcierto inicial y suspensión de presupuestos va a transformarse en una actividad intensa de reconocimiento de aquel universo de elementos y eventos que se nos presentan y que nos interpelan cada vez con una pregunta que Adorno supo plantear muy bien: «¿y para qué todo esto?»; ¿qué con ensamblar precisamente este tipo de modelo de avión y este tipo de imagen religiosa?; ¿qué con estas imágenes que aparecen y desaparecen sobre este tipo de material tan resbaladizo e impermeable?; ¿qué con estos rostros inmensamente grandes que se amoldan a este determinado edificio, y estas voces que impregnan precisamente este espacio determinado por el que camino habitualmente? En la misma dirección de estas preguntas, Paul Valéry planteaba que la obra artística sólo podía ser interpretada adecuadamente si el espectador seguía o recreaba en su acto interpretativo la forma específica de articulación de elementos que allí se presenta (93-5). El aspecto crucial de esta idea radica en que la significación propia de la obra artística dependería de la forma específica de articulación de los elementos que componen la obra. En contraste, dentro del contexto de la significación conceptual y en el habla cotidiana, la especificidad de la articulación de elementos significantes no desempeña un papel tan importante como en el arte. Podemos significar nuestros conceptos y opiniones de varias formas sin afectar radicalmente el significado que deseamos transmitir. Por el contrario, en el acto de significación artística, la presencia particular de los elementos que integran la obra y el modo en que están dispuestos es lo que determina la posibilidad de comunicar un sentido. Martin Seel reformula esta tesis, vía Adorno, de la siguiente manera:

Todo tipo de uso sígnico requiere un medio sensible, pero no todos ellos lo presentan. No todos presentan lo que presentan por medio de una presentación de su medio. Pero así es como sucede con las frases literarias, las armonías musicales y las imágenes artísticas. Estas presentan algo presentándose a sí mismas. Ellas presentan algo únicamente a aquellos quienes las perciben como constelaciones individuales de apariencia (individual en el sentido de no ser reemplazable por ninguna otra combinación de elementos). Esta percepción es dirigida a la simultaneidad de una composición o co-ocurrencia de apariencias. Quien quiera experimentar el contenido de las obras de arte, ha de atender a esta simultaneidad, 
esta interacción, este proceso (como Adorno constantemente enfatiza) de las obras de arte. Su presentación del mundo se revela en cuanto auto-presentación. (Seel, 112-3) ${ }^{2}$

Sin embargo, este tipo de definiciones tienden peligrosamente a aislar la experiencia estética como una especie de esfera desconectada de nuestros demás ámbitos de construcción de sentido, es decir, como una actividad solitaria, fragmentaria y exclusiva de los expertos. Antes bien, la actividad intensa de reconocimiento de cada elemento y evento que se nos presenta y de cómo se nos presenta en una obra artística, remite a una intensa labor de construcción y reconstrucción de significado que parte siempre de horizontes específicos de expectativa, de nuestras formas ya habituales e interiorizadas de entender el mundo y de vivir en él como en nuestra casa. Esto quiere decir que la experiencia estética abre de nuevo los horizontes desde los cuales juzgamos el mundo, a partir de una situación en la cual somos interpelados por una serie muy determinada de elementos y eventos que se nos presentan. Si de cierta manera en el mundo cotidiano ya hemos asumido una forma particular de interpretar las situaciones, los espacios, los tiempos y todo aquello que los puebla, de manera que se han vuelto obvios y familiares; la experiencia estética hace que esas presuposiciones sean puestas en juego una vez más al confrontarlas con esta situación, este espacio, este tiempo, estos objetos, estos cuerpos que componen lo que llamamos aún «obras» de arte. En la experiencia estética, el percibir y el reconocer intensificado están desde siempre unidos a las construcciones de sentido renovadas y por esa razón el asignar determinado significado específico a una obra artística nos resulta comúnmente un acto en cierta medida arbitrario: también podría decirnos algo más.

De hecho, la experiencia estética que se hace de una obra de arte siempre nos dice algo más, no solamente porque la interpelamos desde horizontes de comprensión diferentes, sino también porque podemos ponerla en relación con aspectos diferentes dentro de un mismo horizonte de comprensión. Esta idea es importante porque nos da la oportunidad de subrayar cómo la experiencia estética es en verdad una experiencia en el sentido de que afecta diversos aspectos de lo que Alfred Schutz describía como mundo de la vida: «Por mundo de la vida cotidiana debe entenderse ese ámbito de la realidad que el adulto alerta y normal simplemente presupone en la actitud de sentido común. Designamos por esta presuposición todo lo que experimentamos como incuestionable; para nosotros, todo estado de cosas es aproblemático hasta nuevo aviso» (25).

Esta estructura de comprensión transparente, obvia y familiar para nosotros, no está integrada solamente por las acepciones del mundo objetivo (conocimiento), sino también por nuestras formas de establecer los criterios que orientan y legitiman los comportamientos intersubjetivos (moralidad); y en un tercer lugar, se integra por lo que Jürgen Habermas llama el mundo subjetivo (81). En este contexto, el concepto de experiencia estética implica también la forma en que ésta va más allá de sí misma y puede tener efectos de distintos tipos sobre las funciones del mundo de la vida que llamamos cognitivas, morales y subjetivas. Efectos que podrían entenderse tanto en un sentido positivo (propiciar,

\footnotetext{
All kind of sign use requires a sensuous medium, but not all of them present it. Not all present what they present by way of a presentation of their medium. But this is how things are with literary sentences, musical tones, artistic pictures. These present something by presenting themselves. They present something only to those who perceive them as an individual constellation of appearances (individual in the sense of not being replaceable by any other combination of elements). This perception is directed at the simultaneity of a composition or co-occurrence of appearances. Whoever wants to experience the content of artworks has to attend to this simultaneity, this interaction, this process (as Adorno emphasizes) of artworks. Their presentation of the world transpires as self presentation.
} 
reforzar, recordar) como negativo (cuestionar, relativizar, extrañar), y aun en una amplia escala de matices. Nos encontramos con uno de los problemas de mayor envergadura que se le plantean a la estética y a la teoría del arte actual: ¿cuáles son las relaciones entre la experiencia estética y las funciones cognitiva, moral y subjetiva del mundo de la vida? Para el análisis de esta cuestión, la teoría debe comenzar antes con una revisión del plano institucional del arte (esto es, el plano de realización histórico-social del arte), puesto que la experiencia estética es por sí misma un objeto de estudio histórico, inscrito dentro de la contingencia humana y sus formas heterogéneas de vida social. A continuación, esbozaremos una forma para abordar esta problemática.

\section{Carácter institucional del arte}

La delimitación de lo que es considerado arte respecto a lo que no lo es, implica una actividad atravesada por la configuración de los órdenes sociales. Se trata de delimitar una relación entre dos categorías contrapuestas (arte/no-arte) que obedece al intento social continuo por organizar el inmenso cúmulo de fenómenos, de prácticas y de formas de comprensión que constituye el entorno en el que vivimos. La delimitación de este entorno mediante categorías permite instaurar un orden, coordenadas de navegación y de control, de manera que el entorno ya no es aquel cúmulo caótico, sino un todo articulado al que llamamos mundo. Entiendo por institución precisamente este tipo de categorizaciones que estructuran el entorno y lo transforman en mundo. Desde esta perspectiva, la relación entre arte y no arte es cada vez el resultado de un ejercicio particular de organización del entorno para fijarlo como mundo estructurado e inteligible. Estos ejercicios son, sin embargo, contingentes en el sentido de que son productos humanos, localmente caracterizables e históricamente variables, aunque con frecuencia traspasan los límites regionales y poseen lapsos de duración y de estabilidad considerables.

Antes hemos evocado el análisis de Arthur Danto, para quien la identificación del arte como representación, expresión y exploración de un determinado medio artístico, constituirían formas institucionales que el arte ha poseído desde el Renacimiento hasta el Modernismo (Danto, 70-9). Esta clasificación tiene como criterio básico el de los procedimientos artísticos. Sin embargo, las configuraciones institucionales del arte sólo se pueden entender parcialmente desde este punto de vista, puesto que no se captan las correlaciones existentes entre estas formas de institucionalidad del arte y las estructuras generales de organización social a las que pertenecen. Vamos a utilizar el esquema básico de categorización de las formas institucionales de arte que propone Jacques Rancière para tratar de mostrar que en cada caso el arte es entendido en función de un orden social más amplio. Rancière entiende por formas institucionales del arte los «regímenes de identificación» que han servido históricamente para delimitar el campo artístico desde distintos horizontes y que se pueden caracterizar a partir de tres grandes tipos, a saber, las formas institucionales éticas, representativas y estéticas del arte.

En el primer tipo institucional del arte, denominado ético, no existe propiamente un concepto de arte, sino de imagen en cuanto «tipo específico de entidad», esto es, una forma de ser esencial, particular y diferenciable. Justamente en este sentido, Rancière afirma que «las imágenes son objeto de una pregunta doble: la cuestión de su origen (y 
consecuentemente de su contenido de verdad) y la cuestión de su finalidad o propósito, los usos a los que apunta y los efectos que genera» (The Politics of Aesthetics, 20). El fin de esta caracterización de la particularidad de las imágenes consiste en establecer cómo se relacionan y qué efectos tienen respecto al ethos de una comunidad. Así pues, habrá imágenes verdaderas y provechosas, pero también las habrá falsas y perjudiciales para los órdenes sociales establecidos (y nunca podría concebirse una confusión entre ellas o una transformación de una en otra, pues se trata de tipos específicos de entidades). Rancière propone como paradigma de esta forma institucional del arte la teoría de Platón sobre las artes imitativas y de aquella clase especial de imitaciones que se aleja más de la verdad esencial, generando desviaciones en la estructura social. En las formas institucionales éticas, podríamos concluir, el arte no tiene un papel por sí mismo, sino sólo como imagen del ethos comunitario. Allí sólo existe el arte de una manera subsidiaria en la medida en que sirve a los propósitos de la cohesión social y la afirmación de un orden determinado del mundo.

El segundo tipo de formas institucionales del arte es denominado por Rancière representativo y al mismo tiempo poético, haciendo alusión a Aristóteles. De hecho, la clave aquí es la pareja conceptual poiesis-mimesis. Por una parte, el concepto de mimesis sirve para delimitar el campo específico del arte, en el sentido clásico de las Bellas Artes, en tanto creaciones humanas destinadas a la representación de algo. La imitación no es más que un principio práctico de organización y delimitación del campo de las artes que las diferencia de otros campos distintos, como la artesanía o las artes útiles y aplicadas. Por otra parte, el concepto de poiesis, referido a las diversas formas de hacer, sirve para especificar distintas clases de creación imitativa de acuerdo al objeto, al medio y al modo de imitación, como sostiene Aristóteles. La combinación de estos dos conceptos sirve, al final, para delimitar el campo artístico, diferenciarlo y jerarquizarlo de acuerdo a criterios de modalidades de imitación, perfección de la imitación y de dignidad de lo imitado. Pero al mismo tiempo, este sistema de diferenciación del arte se encuentra profundamente articulado con un interés social, a saber, el de racionalizar las estructuras de organización comunitaria y hacer más eficiente esta organización a través de jerarquías, clases, funciones, deberes y recompensas (Rancière, The politics of aesthetics, 22).

Finalmente, para Rancière, el tercer tipo de institución del arte es el estético. Tal denominación se debe a que en esta forma institucional el criterio decisivo para identificar el arte es la forma sensible específica que adoptan sus objetos. Sin embargo, no se trata de un mero esteticismo. Por el contrario, aislar la forma específica de lo sensible permite su propia reflexión, y eso es justamente lo que identifica a las obras artísticas bajo este tipo de institución. Para Rancière:

en el régimen estético, los fenómenos artísticos son identificados por su adhesión a un régimen específico de lo sensible, el cual es removido de sus asociaciones ordinarias y apropiado por un poder heterogéneo, el poder de una forma de pensamiento que se ha vuelto extraña a sí misma: un producto idéntico a algo no producido, conocimiento transformado en des-conocimiento, logos idéntico a pathos, intención de lo no intencional, etc. Esta idea de un régimen de lo sensible que ha devenido extraño para sí mismo, el lugar de una forma de pensamiento que se ha vuelto extraña para sí misma, es el núcleo invariable en las identificaciones del arte que han configurado el modo estético del pensamiento desde el principio (The Politics of Aesthetics, 23). 
Gracias a este extrañamiento que penetra en las formas específicas de lo sensible, el arte puede ser identificado en esta forma institucional al mismo tiempo como un campo autónomo y como una forma de reflexión, activa y crítica, acerca de las formas en las que nuestras sociedades están organizadas.

Cada una de estas formas institucionales del arte intenta interpretar y asignar un lugar dentro del orden social general a aquellas formas de actividad humana en las cuales la articulación de sentido se hace a partir de la presentación sensorial. Niklas Luhmann propone que el desarrollo social del arte debe leerse justamente como el intento continuo de integrar a una estructura de mundo aquello más resistente a la comprensión racional, a saber, la experiencia de lo sensorial en su especificidad, su momentaneidad y las intensidades emotivas con que se percibe (Luhmann, 235). Que esta integración pueda darse tanto en el sentido de la afirmación de un ethos y de unas jerarquías sociales, como en el sentido del potencial de crítica que representa, puede explicarse a partir de la misma estructura de la experiencia estética. Por una parte, la experiencia estética implica la reactivación del sujeto frente a su realidad circundante, de modo que cada experiencia es siempre particular y opuesta a las formas convencionalizadas de comprensión y de acción. Se trata de una ruptura o una salida de los comportamientos rutinarios de la vida cotidiana que apela fundamentalmente a la exploración renovada e imaginativa de nuestros mundos ${ }^{3}$. Por otra parte, en la experiencia estética, la relación sujeto-objeto se vuelve fluida y se despliega una suerte de co-pertenencia de ambos términos de la relación. Aunque se trata de una experiencia y en cuanto tal se da en la conciencia del sujeto, sin embargo, siempre se trata de una experiencia de algo otro, diferente, que no hacía parte integral de mi experiencia previa ni de mi mundo o que sólo ocupaba allí un espacio marginal, olvidado o reprimido. A través de este proceso, el sujeto experimenta una ampliación de sus horizontes de comprensión de modo que puede apropiarse incluso de vivencias lejanas a su realidad, como formas de religiosidad del pasado, inquietantes e incluso extremas, como la violencia. A este rasgo fundamental de la experiencia estética se refería Hans Robert Jauss cuando señalaba que el término alemán para el gozo estético (Geniessen) unificaba los conceptos de participación y apropiación: «En el acto estético el sujeto disfruta siempre de algo más que de sí mismo: se siente en la apropiación de una experiencia del sentido del mundo, que puede descubrirle tanto su propia actividad productora como la recepción de la experiencia ajena [...]» $(73)^{4}$.

Estas dos características de la experiencia estética han sido interpretadas de modos diferentes en cada forma institucional del arte. En las formas éticas, el acento parece recaer en la característica descrita como co-pertenencia de sujeto y objeto, tal y como se presentaría, por ejemplo, en la formulación platónica de la belleza como una experiencia en la que el sujeto participa del mundo ideal a través de su reflejo en la experiencia sensorial del objeto contemplado (Platón, 249). La co-pertenencia de sujeto y objeto en la experiencia estética se entiende así como despliegue de la identificación del sujeto respecto a la revelación de sentido que ocurre en la obra y que se asume como criterio decisivo del ethos comunitario. Por el contrario, en las formas institucionales estéticas del arte, el acento tiende a recaer más bien en la característica de la experiencia estética que describimos como suspensión de los mundos cotidianos de comportamiento y comprensión, tal

Esta característica de la experiencia estética se ha elaborado a través de motivos como el de la visión poética, la imaginación redentora y el extrañamiento (Abrams, 1992).

4 La co-pertenencia de objeto y sujeto en la experiencia estética ha sido tematizada especialmente bajo el concepto de juego (Gadamer, 31). 
y como lo presenta Adorno mediante la lógica de lo no-idéntico y de la negatividad. Esta ruptura del mundo de la vida cotidiana se traduce aquí como «negación determinada» de los órdenes sociales dados y en consecuencia como una proyección de las posibilidades de cambio.

\begin{tabular}{|l|l|l|l|}
\hline & $\begin{array}{l}\text { Forma } \\
\text { institucional ética } \\
\text { del arte }\end{array}$ & $\begin{array}{l}\text { Forma institucional } \\
\text { representativo-poética } \\
\text { del arte }\end{array}$ & $\begin{array}{l}\text { Forma institucional estética } \\
\text { del arte }\end{array}$ \\
\hline $\begin{array}{l}\text { Co-pertenencia } \\
\text { de sujeto y objeto } \\
\text { en la experiencia } \\
\text { estética. }\end{array}$ & $\begin{array}{l}\text { Arte como forma } \\
\text { de expresión de un } \\
\text { ethos comunitario } \\
\text { característico. }\end{array}$ & $\begin{array}{l}\text { Arte como forma de } \\
\text { representación de } \\
\text { ordenes y jerarquías } \\
\text { sociales. }\end{array}$ & $\begin{array}{l}\text { Arte como manifestación } \\
\text { de una perspectiva de } \\
\text { transformación social que } \\
\text { cuestiona un estado de cosas } \\
\text { dado. }\end{array}$ \\
\hline $\begin{array}{l}\text { Particularidad } \\
\text { de la experiencia } \\
\text { estética. }\end{array}$ & $\begin{array}{l}\text { Arte como medio } \\
\text { de interiorización } \\
\text { de elementos de } \\
\text { cohesión social. }\end{array}$ & $\begin{array}{l}\text { Arte como forma de } \\
\text { asimilación de las } \\
\text { estructuras jerárquicas } \\
\text { de la sociedad. }\end{array}$ & $\begin{array}{l}\text { Arte como medio de liberación } \\
\text { de las formas convencionales } \\
\text { de pensamiento y } \\
\text { comportamiento. }\end{array}$ \\
\hline
\end{tabular}

Por diferentes que puedan llegar a ser las configuraciones sociales de la institución arte, éstas pueden comprenderse como formas de realización histórica de la capacidad humana para producir intencionalmente fenómenos de significación que supongan y exijan una función estética de la conciencia humana como elemento estructural. En cada momento histórico, las formas institucionales del arte guardan relaciones muy estrechas con estructuras generales de organización social, de manera que parecen moldearse mutuamente y hacen estallar las estrechas dicotomías de compromiso y autonomía, negación y afirmación. En el apartado final propondremos, entonces, una reflexión aún provisional acerca de las consecuencias que los análisis históricos de las formas de institucionalidad del arte arrojan sobre el problema de la función social del arte. Para ello, me valdré de los análisis recientemente realizados por dos filósofos que provienen de tradiciones diferentes: Christoph Menke y Jacques Rancière.

\section{RELACIÓN ENTRE ARTE Y SOCIEDAD}

La pregunta por la relación entre arte y sociedad ya no busca poner en evidencia las formas de realización histórica del arte, formas que he llamado institucionales y que pueden ser caracterizadas y diferenciadas. Lo que busca en cambio es indagar si, a partir de las diferentes formas institucionales, se puede inferir la función del arte en el desarrollo social. Así pues, el punto de partida en esta dirección lo constituye el vínculo que las formas institucionales del arte proyectan entre la producción de obras artísticas (entendidas como fenómenos de significación basados en una función estética de la conciencia) y los procesos de articulación de mundo (entendidos como procesos de estructuración y reestructuración de las formas de comprensión y relación de los sujetos entre sí y con el entorno), esenciales para constituir y transformar una sociedad. ¿Qué tipo de vínculo es el que se produce, pues, entre obras de arte y articulación de mundo? 
En la reflexión acerca de esta interrogante debemos volver a la idea antes mencionada según la cual el arte forma parte de los procesos de comprensión de los cuales depende la articulación del mundo. El arte no está por fuera de esta labor comprensiva e interpretativa, sino que es parte de ella, constituye una forma de este comprender e interpretar que produce mundo, y la comprensión de éste debe especificarse recurriendo especialmente a su carácter estético. El carácter estético del arte es lo que lo convierte en una práctica estrechamente relacionada con el percibir y el reconocer intensificado, exploratorio e imaginativo del mundo, tanto desde el punto de vista de su producción, como desde el punto de vista de su recepción. En el percibir y el reconocer intensificado la actividad interpretativa y comprensiva del mundo debe volver a ponerse en marcha más allá de los resultados previamente obtenidos o interiorizados. Incluso si aquello con lo que una obra nos pone en relación es algo previamente conocido por nosotros, un objeto, un espacio, un cuerpo o una situación cotidiana, su efecto es el del extrañamiento: nos obliga a hacer nuevamente la experiencia de tal objeto y a producir una nueva interpretación suya. De este modo el vínculo que el arte guarda con los procesos de articulación de mundo se caracteriza por abrir estos últimos a revisiones y transformaciones evitando que se clausuren o renovándolos permanentemente.

Desde dos puntos de vista diferentes, Christoph Menke y Jacques Rancière han analizado esta función del arte respecto a la articulación de mundo bajo las categorías de soberanía del arte y de política. Para Menke la soberanía del arte consiste en la crisis que se genera en los discursos y las formas de comprensión no estéticas del mundo desde la esfera del arte, una vez ésta ha abierto la comprensión a su propio carácter contingente y procesal. Para ello, según Menke, el arte despliega una lógica de la negatividad en la cual encontramos nuevamente descrita la estructura de la experiencia estética. En ella, la particularidad fenoménica de la configuración de la obra de arte no desaparece simplemente en una síntesis interpretativa que le asigna un sentido determinado. Por el contrario, para Menke lo característico de este proceso de experiencia estética en el arte radica en la tensión continua de estos dos elementos: la particularidad fenoménica de la obra y la síntesis interpretativa que hacemos de ella en el proceso de recepción. La consecuencia de esta tensión consiste en que la comprensión misma queda «indefinidamente aplazada» de modo que cada acto de comprensión se revela como un acto contingente o provisional, nunca definitivo (Menke, 68). Es esta experiencia de la provisionalidad de la comprensión lo que desde el arte puede someter a crisis las formas de comprensión del mundo demasiado rígidas o naturalizadas.

Por su parte, Jacques Rancière ha analizado este vínculo del arte con los procesos de articulación de mundo desde un concepto revitalizado de política que no puede confundirse con el viejo concepto de compromiso. Para Rancière la dimensión política del arte consiste en la redistribución del orden del mundo por el cual se designa la legitimidad de ciertas formas de vida, de comprensión, de lenguaje, de comportamiento y de aparición sensible. En este proceso, lo que se pone en juego es la distribución previa del mundo y, consecuentemente, la legitimidad que ha sido otorgada a ciertas formas de vida sobre otras, a ciertas formas de comprensión sobre otras, y finalmente, a ciertas formas de lenguaje, de comportamiento y de aparición sensible sobre otras. Tal redistribución, sin embargo, ocurre gracias a la articulación de la obra en la medida en que ésta presenta una manera particular de poblar su espacio y su tiempo propio. Pero la "constitución propia de un determinado espacio/tiempo» de la obra de arte no es otra cosa que su 
aparecer fenoménico particular: la relación de movimientos en el espacio del actor y del bailarín, la relación de palabras del texto literario, la relación de sonidos en el tiempo. Más aún, Rancière sostiene que «las prácticas del arte in situ, el desplazamiento del cine en las formas espacializadas de la instalación museística, las formas contemporáneas de espacialización de la música o las prácticas actuales del teatro y de la danza van en la misma dirección: la de la convergencia hacia una misma idea y práctica del arte como forma de ocupar un lugar en el que se redistribuyen las relaciones entre los cuerpos, las imágenes, los espacios y los tiempos» (Rancière, Sobre políticas estéticas, 17).

A diferencia de Menke - quien trata de reinterpretar el concepto de negatividad estética para superar tanto las recargas hermenéuticas de la idea del arte como forma de comprensión o recargas deconstruccionistas que lo ven como una forma de manifestación de lo inconmensurable-, para Rancière el desafío es cuestionar la idea de la finalización del vínculo reconocido por la modernidad entre arte y política, con el ascenso de nuevas prácticas artísticas en la era postmoderna. Pero en uno y otro autor, encontramos que la función social del arte es entendida en términos de la capacidad de renovar las formas de comprensión del mundo institucionalizadas, de las cuales dependen a su vez las distribuciones de los roles y las jerarquías de los modos de vida. Ambos coinciden además en relacionar esta función con las maneras específicas en las que las obras construyen desde su propia articulación de materiales una experiencia nueva del mundo.

Sin embargo, es Rancière quien llama la atención sobre lo que él denomina la «contradicción originaria continuamente en marcha»: "la soledad de la obra contiene una promesa de emancipación. Pero el cumplimiento de la promesa consiste en la supresión del arte como realidad aparte, en su transformación de una forma de vida» (Rancière, Sobre politicas estéticas, 29). En esta contradicción originaria de la modernidad estética, considero que Rancière alcanza el núcleo del problema del arte y su relación con la sociedad. Aunque el arte no es simplemente una forma de interpretación y articulación del mundo, pues se especifica mediante su dimensión estética fundamental, el arte es también una forma de interpretación orientada hacia la articulación de mundo, que apunta a nuevas posibilidades de vida social. Lo que especifica al arte es su manera particular de realizar la comprensión del mundo a través de la conciencia estética, pero ello no suprime la pertenencia del arte a la actividad general del ser humano orientada a la comprensión del mundo. Por el contrario, el arte se revela como comprensión del mundo más intensamente cuanto mayor es su capacidad de configurar espacios particulares de presentación y encuentro con aquello que está fuera de orden, ha quedado olvidado o ha sido sobreentendido, es decir, con aquello que se ha vuelto incomprensible.

Así regresamos inesperadamente al punto de partida: ¿qué significa preguntar por el arte? Significa, desde esta perspectiva, indagar cómo se ponen en relación los complejos procesos de comprensión de mundo y estructuración social, con la capacidad humana de articulación y experimentación estética del mundo. El arte no surge como esfera radicalmente separada de los procesos de construcción de mundo, sino como realización suya mediante la capacidad estética de articulación y experimentación. La acogida estética de la construcción de mundo diferencia al arte de otras esferas, pero al ponernos en relación con aquello que ha quedado apresado en nuestras formas acostumbradas de experiencia de mundo, nos obliga a recomenzar nuestra labor de comprensión y mantiene así abiertos los procesos de formación de mundo. 


\section{REFERENCIAS}

Abrams, Meyer Howard. El romanticismo: tradición y revolución. Madrid: Visor, 1992. Medio impreso.

Adorno, Theodor W. Teoría Estética. Madrid: Akal, 2004. Medio impreso.

Bürger, Peter. Teoría de la vanguardia. Barcelona: Península, 1997. Medio impreso.

Danto, Arthur. Después del fin del arte. Buenos Aires: Paidós, 2006. Medio impreso.

Ferrari, León. La civilización occidental y cristiana. Buenos Aires: Fundación Augusto y León Ferrari - Arte y Acervo, 1965. Ensamblaje artístico.

Gadamer, Hans Georg. Actualidad de lo bello. El arte como juego, simbolo y fiesta. Barcelona: Paidós, 1991. Medio impreso.

. Verdad y método. Salamanca: Sígueme, 1996. Medio impreso.

Gómez, Laureano. «El expresionismo como síntoma de pereza e inhabilidad en el arte». En Obras completas, de Laureano Gómez, 162-173. Bogotá: Instituto Caro y Cuervo, 1984 [1937]. Medio impreso.

Habermas, Jürgen. Teoría de la acción comunicativa. Tomo I. II vols. Madrid: Taurus, 1981. Medio impreso.

Jauss, Hans Robert. Experiencia estética y hermenéutica literaria. Ensayos en el campo de la experiencia estética. Madrid: Taurus, 1986. Medio impreso.

Luhmann, Niklas. El arte de la sociedad. México: Herder, 2005. Medio impreso.

Lyotard, Jean Francois. Lo inhumano: charlas sobre el tiempo. Buenos Aires: Manantial, 1998. Medio impreso.

Menke, Christoph. Soberanía del arte. La experiencia estética según de Adorno y Derrida. Madrid: Visor, 1997. Medio impreso.

Muñoz, Oscar. Aliento. Bogotá: Museo de Arte del Banco de la República, 1995. Objeto artístico.

Platón. Fedro o de la belleza. Buenos Aires: Aguilar, 1965. Medio impreso.

Rancière, Jacques. The politics of aesthetics. The distribution of the sensible. New York: Continuum, 2004. Medio impreso.

. Sobre políticas estéticas. Barcelona: Universidad Autónoma de Barcelona, 2005. Medio impreso.

Schutz, Alfred, y Thomas Luckmann. Las estructuras del mundo de la vida. Buenos Aires: Amorrortu editores, 2009. Medio impreso.

Seel, Martin. The Aesthetics of appearing. Stanford: Stanford University Press, 2005. Medio impreso.

Valéry, Paul. Teoría poética y estética. Madrid: Visor, 1990. Medio impreso.

Wellmer, Albrecht. Sobre la dialéctica de modernidad y posmodernidad. La crítica de la razón después de Adorno. Madrid: Visor, 1993. Medio impreso.

Wodiczko, Krzysztof. Tijuana Projection. Tijuana: Centro Cultural Tijuana, 2000. Medio audiovisual.

Zalamea, Jorge. "Nueve artistas colombianos». Literatura, política y arte. Bogotá: Instituto Colombiano de Cultura, 1978. 271-310. Medio impreso.

Recepción: Febrero 2012

Aceptación: Mayo 2012 